\title{
Numerical Simulation on determining technological parameters of vibratory aging treating for large-sized welding box-section beam \\ structure
}

\author{
Fu Jian-ke $e^{1, a^{*}}$, Jin Jun $^{1}$, Zhou Xing $^{1}$ \\ College of Mechanical \& Power Engineering,China Three Gorges University, Yichang 443002,China \\ aworkjj@163.com
}

Key Words: Vibratory stress relief ; Technological Parameters ;Box-Section Beam Structure ;Finite element

\begin{abstract}
In order to determining technological parameters of vibratory aging treating for large-sized welding box-section beam structures, kinetic analysis was carried out according to the industrial standard. The natural frequency, vibration mode and the curves of amplitude-frequency were obtained by using Finite Element Analysis (FEA). This gave some suggestions for reference no how to determine the technological parameters for large-sized welding structures.
\end{abstract}

\section{Introduction}

The existence of residual stresses caused by the welding process is an important reason of cracking and distortion in welded metal structures that may affect the life and dimensional stability significantly. Therefore, the reduction or elimination of the residual stress is an essential task in the manufacturing industries of metals.

The Vibratory stress relief(VSR) has been demonstrated to possess some especial characteristics for stress relief, such as a lower the peak residual stresses, a smoother the distribution of the residual stresses and more convenient operation[1 3]. However , it is difficult to determine the technological parameters of VSR for the large welding structure, so that the application of the VSR is limited, especially for the large-sized welding box-section beam structures.

The structure shown in Fig.1 was a box-section beam structure of access gate in one large lock. It was welded by plates, which made up by panels、 upper webs、 next webs 、 clapboards, and rear flange plates. Clearly, the application of the vibratory aging treating was a practical alternative to the reduction of the residual stresses for this large-sized welding structure. However, it was difficulty to verify appropriate technological parameters of the vibratory aging treating by a traditional method. The aim of this work was to determine technological parameters of vibratory aging treating by finite element method for large-sized welding box-section beam structures. 


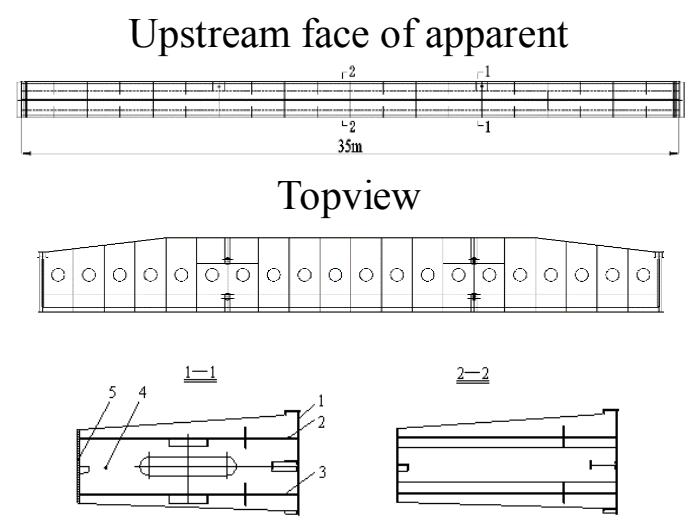

Fig.1 Diagram of access gate structure

1panels 2upper webs 3next webs 4 Clapboard 5Rear flange plate

\section{The finite element model of the access gate structure}

The mechanical properties of the materials are shown in Table 1.

TABLE 1. MECHANICAL PROPERTIES OF PROPERTY OF Q345

\begin{tabular}{|c|c|c|c|c|}
\hline $\begin{array}{c}\text { yield limit } \sigma_{\mathrm{s}} \\
(\mathrm{MPa})\end{array}$ & $\begin{array}{l}\text { Ultimate strength } \\
\qquad \sigma_{\mathrm{b}}(\mathrm{MPa})\end{array}$ & $\begin{array}{l}\text { Elongation } \\
\delta \%\end{array}$ & $\begin{array}{l}\text { elastic } \\
\text { modulus } \\
\mathrm{E}(\mathrm{MPa})\end{array}$ & poisson ration $\mu$ \\
\hline 345 & 509.6 & 21 & $2.06 \times 10^{5}$ & 0.3 \\
\hline
\end{tabular}

Because the large-sized welding box-section beam structures were fabricated with formed plates welded together, the board shell unit was used to establish the body frame finite element model, and the mesh is shown in Fig. 2, which contained 160239 nodes and 162353 elements. This finite element model had a good quality of the generated grid and no warnings and errors were occurred for the unit shape checking after the meshing

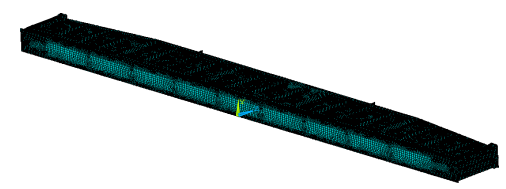

Fig.2 Finite element model of the access gate structure

\section{Dynamic analysis of the access gate structure}

Calculations of Natural Frequency.The natural frequency and the mode shapes of box-section beam were an important parameter to the subsequent dynamic analysis, so it was essential to calculate the natural frequency of box-section beam at first. On the other hand, natural frequency and the mode shapes were varied due to different supporting conditions for box-section beam, so actual conditions should be taken into consideration for the calculations of natural frequency.

Fig. 3 shows the supporting way of box-section beam structures. The main purpose of vibratory aging treating was reduction of the longitudinal residual stress between the webs and rear flange plates and the transverse residual stress between the clapboards and the rear flange plates, so 
the vibration mode was the access gate stricture bend vertically.

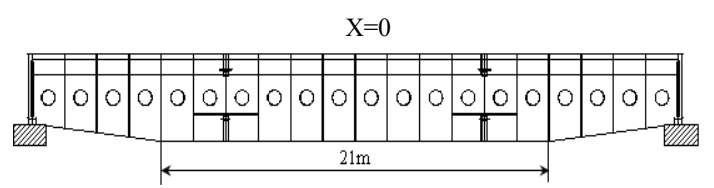

Fig.3 Supporting way of access gate structure

After the model was established, the modal analysis of the access gate structure was carried out to solving the vibration characteristics. The natural frequencies from the first order to the fifth order was shown in Table. 2

Table 2 Natural frequency of the first five orders for access gate structures $/ \mathrm{Hz}$

\begin{tabular}{cccccc}
\hline Order & $\mathrm{f1}$ & $\mathrm{f} 2$ & $\mathrm{f} 3$ & $\mathrm{f} 4$ & $\mathrm{f5}$ \\
\hline Natural frequency & 4.435 & 10.666 & 12.857 & 15.359 & 22.741 \\
\hline
\end{tabular}

The vibration mode displacement from the first order to the third order of box-section beam structures was shown in Fig. 4. It can be seen that lateral displacement occurred along the y-axis at the natural frequency of the first order. As for the natural frequency of the second order, the lateral displacement along the $\mathrm{z}$-axis was present, which was the excepted vibration mode. When the natural frequency was the third order, the wavy vibration was occurred. Obviously, the natural frequency of the second order was beneficial to the reduction of residual stress according to the results as motioned above, so the frequency of the second order were the main vibration frequency.

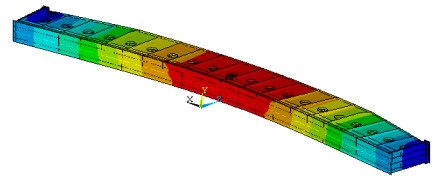

a. Vibration mode displacement of the first order

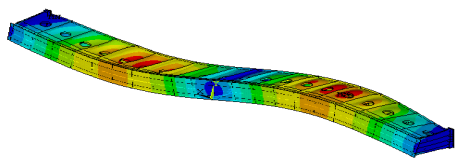

c. Vibration mode displacement of the third order

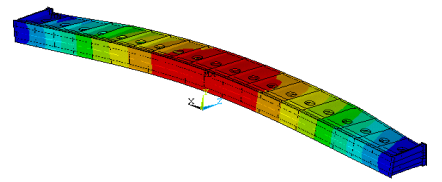

b. Vibration mode displacement of the second order

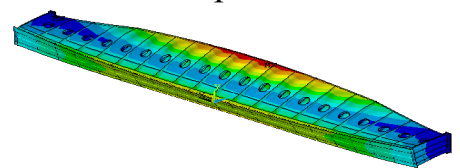

d. Vibration mode displacement of the third order

Fig.4 Vibration mode displacement from first order to third order

Determination of Excitation Frequency.As motioned above, the main vibration frequency of the access gate structure was the second order natural frequency in order to reduce the residual stress in the weld between the webs and rear flange plates and the residual stress between the clapboard and the rear flange plate.

At the vibration mode of the second order, the displacement at middle of the access gate structure was he maximum. So, the exciter should be fixed at the middle of the panel of the access gate structure when the supporting way of box-section beam structures was taken into consideration. Accordingly, the vibration pickup can be fixed at the middle of the rear flange plates.

On the other hand, the natural frequency can not serve as the main vibration frequency according to the requirements specified in the Chinese standard GBT5926-2005. Instead, the frequency whose vibration amplitude corresponded to the one third to two third of the main vibration amplitude on the rising edge was reasonable when the vibratory aging treating was carried out. So, amplitude frequency response characteristics were further analyzed, and Fig. 5 is the curves of 
amplitude-frequency of twelve random dots at the middle of rear flange plate when the frequency was in the range from $10.066 \mathrm{HZ}$ to $11.166 \mathrm{HZ}$.

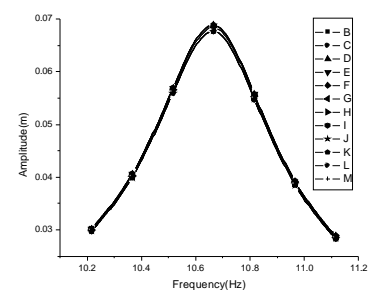

Fig.5 Amplitude-frequency curve of the access gate structure

It can be see that the tendency of vibration displacement of different random dots was the same, which was in accordance with the harmonic characteristic of the main vibration amplitude. When the frequency was $10.666 \mathrm{HZ}$, the resonance appeared. So the displacement was the maximum at the frequency $10.666 \mathrm{HZ}$. At the same time, the further away from the resonant frequency was, the lower of vibration amplitude was. The calculations showed that the vibration amplitude of the frequency of $10.366 \mathrm{~Hz}$ was in the range of the one third to two third of the main vibration amplitude. In addition, this frequency met the requirements specified in the Chinese standard GBT5926-2005. So, the frequency of $10.366 \mathrm{~Hz}$ was excitation frequency.

Determination of Excitation Force.The excitation force was a key parameter of vibratory aging treating, so the determination of excitation force must be optimum. When excitation force was too small, the vibratory aging treating had little effect on the reduction of the residual stress. On the contrary, a bigger excitation force resulted in the partial fatigue failure. According to the specifications shown in the Chinese standard GBT5926-2005, dynamic stress amplitude produced by the excitation force can be expressed as: $\left(\sigma_{b}-\sigma_{s}\right) / 3 \leq \sigma_{d} \leq \sigma_{b} / 3$, where $\sigma_{b}$ was the tensile strength, $\sigma_{s}$ was the yield limit, $\sigma_{\mathrm{d}}$ was the excitation force. So, dynamic stress amplitude was in the range from $55 \mathrm{MPa}$ to $170 \mathrm{MPa}$ according to the material property shown in the Table 2.

On the other hand, the excitation force also can be expressed as: $F=A \sin 2 \pi \mathrm{ft}$, where A was the amplitude of excitation force, $f$ was the excitation frequency. In present study, we were particular focus on excitation force of invariant cross section with the span of $21 \mathrm{~m}$ in the middle of box-section beam. The dynamic stress distributed in weld between webs and flange plate was shown in Fig.6. It can be seen that dynamic stress was the maximum at the middle of box-section beam, and gradually decreased from the middle to the two ends. In addition, the equivalent value of dynamic stress on the concerned parts is symmetrical distribution by the center line of access gate structure, which was agreed with the displacement distribution of main vibration mode.

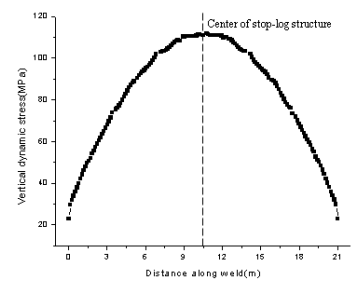

Fig.6 Distribution of amplitude of dynamic stress in the weld between webs and rear flange plates According to the national industry standard of the vibration aging, when the amplitude of dynamic stress is above $55 \mathrm{MPa}$, the exciting force will meet the standard. It can be seen that the longitudinal dynamic stress was 55.493MPa and 56.181MPa when horizontal coordinate was 1.969 and 19.031 respectively. Consequently, the longitudinal dynamic stress in the weld seam between 
web plate and flange plate was greater than $55 \mathrm{MPa}$ at the middle of box-section beam with a span of $8.5 \mathrm{~m}$. Clearly, the residual stress in this range could be reduced when vibratory aging treating was carried out with the excitation force of $10000 \mathrm{~N}$ and excitation frequency of $10.366 \mathrm{~Hz}$.

According to the symmetry of the structure, the amplitude of dynamic stress for the place between clapboards and rear flange plates with horizontal coordinate $\mathrm{x}=0 \mathrm{~m}, 3.5 \mathrm{~m}, 7 \mathrm{~m}, 10.5 \mathrm{~m}$ in Fig. 3 were investigated, as shown in the Table 3. It can be seen that the transverse dynamic stress in weld between clapboard and flange plate from the left side $7 \mathrm{~m}$ to right side $7 \mathrm{~m}$ about the central of access gate structure was greater than 55MPa. Therefore, the effective range of weld between clapboard and flange plate treated by VSR was $14 \mathrm{~m}$.

Table. 3 Amplitude of dynamic stress in the weld between clapboard and rear flange plates

\begin{tabular}{ccccc}
\hline location of clapboard $(\mathrm{m})$ & $\mathrm{x}=0$ & $\mathrm{x}=3.5$ & $\mathrm{x}=7$ & $\mathrm{x}=10.5$ \\
\hline Transverse dynamic stress $(\mathrm{MPa})$ & 93.08 & 91.22 & 65.80 & 30.04 \\
\hline
\end{tabular}

\section{Conclusion}

Numerical simulation on the determining technological parameters of vibratory aging treating for the box-section beam structures was carried out by finite element method. This gave some suggestions for reference no how to determine the technological parameters for large-sized welding structures.

The excitation position, excitation frequency and excitation force were calculated, the results showed that the residual stress could be reduced when vibration exciter was fixed to the middle of the panels with the excitation force of $10000 \mathrm{~N}$ and excitation frequency of $10.366 \mathrm{~Hz}$.

\section{REFERENCES}

1 Zhang Defen; Yin Chengjiang;Chen Xiaowen;

Wan Fating;Song Tianmin.Overview on effect and mechanism of vibration aging. Journal of

Fushun Petroleum Institute, 2000,1(20): $48 \sim 52$

2 Munsi A.S.M.Y,Waddell A.J,Walker C.A.The influence of vibratory treatment on the fatiguelife of welds:A comparison with thermal stress relief.British Society for Strain Measurement , 2001,4(37):141 149 .

3 Bai lingwu , Bai yuhui, Tu junqi . The discussion of The VSR technology . Sichuan Metallurgy , 2002(1):42 43 